Original Research Paper

\title{
Analysis of the Omega-3 Fatty Acids Content in Commercial Omega-3 Supplements in Arab Gulf Countries
}

\author{
${ }^{1}$ Fatmah Alghamdi, ${ }^{2}$ Mohammed G. Embaby, ${ }^{3}$ Mevlüt Günal and ${ }^{4}$ Amer A. AbuGhazaleh \\ ${ }^{1}$ Department of Animal Science, Food and Nutrition, Southern Illinois University, 62901-Carbondale, IL-USA \\ ${ }^{2}$ Department of Animal Science, Food and Nutrition, Southern Illinois University, 62901-Carbondale, IL-USA \\ ${ }^{3}$ Department of Animal Science, Isparta University of Applied Sciences, 32260-Isparta-Turkey \\ ${ }^{4}$ Department of Animal Science, Food and Nutrition, Southern Illinois University, 62901-Carbondale, IL-USA
}

\author{
Article history \\ Received: $13-10-2020$ \\ Revised: 08-12-2020 \\ Accepted: 11-12-2020 \\ Corresponding Author: \\ Amer A. AbuGhazaleh \\ Department of Animal Science, \\ Food and Nutrition, Southern \\ Illinois University, 62901, \\ Carbondale, IL-USA \\ Email: aabugha@siu.edu
}

\begin{abstract}
The objective of this study was to analyze and compare the eicosapentaenoic acid (C20:5n3; EPA) and docosahexaenoic acid (C22:6n3; DHA) content of omega-3 supplements sold in Arab Gulf Countries with the contents claimed on the product label. Thirty-one commercial supplements purchased from stores in 3 different countries (Saudi Arabia, Kuwait and Bahrain) had their fatty acid composition and content were analyzed using gas-chromatograph with a $100 \mathrm{~m}$ SP-2560 fused silica capillary column. The range of measured EPA was 5.09 to $469.63 \mathrm{mg}$ per capsule and for DHA was 10.47 to $357.26 \mathrm{mg}$ per capsule. The percentage of the stated label amount for EPA and DHA ranged from 6.5 to $138.6 \%$ and 10.9 to $126.3 \%$, respectively. Using the U.S. Food and Drug Administration (FDA) labeling requirements where a supplement must contain at least $80 \%$ of the stated label amount of each component listed, only $43.8 \%$ of the supplements were compliant for EPA and $40.6 \%$ were compliant for DHA. Additionally, only $21.9 \%$ of the measured EPA and DHA fall within the $10 \%$ of the stated label amount. These results demonstrate that omega-3 supplements sold in Arab Gulf Countries is not being properly controlled by manufacturers or government agencies and quality testing is needed to ensure compliance.
\end{abstract}

Keywords: Fatty Acids Content, Commercial Brands, Omega-3 Supplements, Arab Gulf Countries

\section{Introduction}

During the past few decades, awareness towards the benefits of omega-3 fatty acids in human health and disease prevention has been increased. Well-documented research supports benefits of omega-3 fatty acids with reduction of cardiovascular morbidity and mortality, infant development, cancer prevention, optimal brain and vision functioning, arthritis, hypertension, diabetes mellitus and neurological/neuropsychiatric disorders (Tapiero et al., 2002; Defilippis et al., 2010; Kaur et al., 2014).

Marine products, nuts, seeds and vegetable oils are rich sources of omega-3 fatty acids (Hunter, 1990; Kinsella, 1990; Whelan and Rust, 2006). Global health organisations recommend daily intake of 250-1000 mg EPA+DHA (GOED, 2019). However, there is a large gap between the actual and the recommended intake of omega-3 fatty acids. Due to low intakes of omega-3 fatty acids rich foods in many western populations, the supplementation of omega-3 fatty acids capsules to diets seem to be the easiest and the quickest way to elevate the level of omega-3 fatty acids intake. Such products are sold in grocery retailers, pharmacies, health stores, internet retailing and others drug stores in many western societies. The global omega-3 market size was estimated at $\$ 2.29$ billion in 2018 and was estimated to expand at a Compound Annual Growth Rate (CAGR) of $9.7 \%$ from 2019 to 2025 (Grand View Research, 2019). Population in Arab Gulf Countries are facing epidemic of obesity and its metabolic syndrome. A study by (Al-Rubeaan et al., 2014) showed that the prevalence of type-2 diabetes mellitus is $25.4 \%$. In a study, (Alhyas et al., 2011) reported the prevalence of overweight and obesity in adults in the region was 2550 and $13-50 \%$, respectively. The dramatic rise in diabetes and obesity represents a real threat to the population and signifies an increased risk of coronary artery disease if left untreated. Rising demand for supplements and functional foods along with increasing disposable income in Arab Gulf Countries 
region is anticipated to boost the omega-3 market growth over the forecast period. The omega-3 products market in Middle East and Africa was expected to register a CAGR of $7.8 \%$, during the 2019-2025 period (Grand View Research, 2019).

Intake of omega-3 fatty acids capsules was found to have positive effects in cardiovascular health, endothelial cell function and body immunological defense (Stenson et at., 1992; Holub and Holub, 2004; $\mathrm{Vu}$ et al., 2019). However, some consumer organizations and the results of some researches indicate that the composition and quality of omega-3 fatty acids supplements available on the market might not meet the proposed quality requirements (Albert et al., 2015; Kleiner et al., 2015; ConsumerLab, 2019). The growth in the popularity of the health benefits of omega- 3 fatty acids in recent years has led to rapid growth in the number of omega-3 supplements available to consumers. Therefore, it is important that label claims for EPA and DHA are accurate. The objective of the current research was to determine and compare omega-3 fatty acids content of omega-3 supplements sold in Arabic Gulf Countries with their label claims.

\section{Materials and Methods}

The purchases of omega-3 supplements samples were from three different countries (Saudi Arabia, Kuwait and Bahrain). Thirty-one omega-3 supplements sold in these countries was selected for this study. Supplements were from different stores and at various times of the year. From each supplement brand, we used a minimum of two samples (2 to 6 ) with different production dates to avoid bias related to seasonal variations. There were, however, two brands, where only one sample was used. Samples were air shipped to the USA and then immediately stored at $4{ }^{\circ} \mathrm{C}$ until analyzed for fatty acids content. We excluded samples with apparent damages to containers/bottle or seals from this study. Supplements brand name, country of production and production dates are presented in Table 1. From every containers/bottle, oil from 4 different capsules was extracted and combined to obtain a composite sample for fatty acids analysis.

Table 1: Omega-3 supplements products information

\begin{tabular}{|c|c|c|c|c|c|c|}
\hline Product name & $\begin{array}{l}\text { Country of } \\
\text { production }\end{array}$ & $\begin{array}{l}\text { Production } \\
\text { date }\end{array}$ & Antioxidant & Type of oil EPA (mg) & DHA (mg) & \\
\hline Maxepa Forte & UK & Jun 2017 & Vit E & & 310 & 210 \\
\hline Maxepa Forte & UK & Jun 2018 & Vit E & & 310 & 210 \\
\hline Bio Marine & Denmark & Mar 2017 & & & 190 & 110 \\
\hline Bio Marine & Denmark & Aug 2017 & & & 190 & 110 \\
\hline Bio Marine & Denmark & Feb 2017 & & & 190 & 110 \\
\hline Bio Marine & Denmark & Mar 2018 & & & 190 & 110 \\
\hline Jamieson & Canada & Oct 2017 & & $\begin{array}{l}\text { Wild salmon } \\
\text { and fish oil complex }\end{array}$ & 180 & 120 \\
\hline Jamieson & Canada & Aug 2017 & & $\begin{array}{l}\text { Wild salmon } \\
\text { and fish oil complex }\end{array}$ & 180 & 120 \\
\hline Vitabiotics & UK & Feb 2017 & Vit E & & 165 & 116 \\
\hline Vitabiotics & UK & Apr 2017 & Vit E & & 165 & 116 \\
\hline JP Omega 3 & KSA & Mar 2017 & & & 170 & 85 \\
\hline JP Omega 3 & KSA & May 2017 & & & 170 & 85 \\
\hline JP Omega 3 & KSA & Jan 2017 & & & 170 & 85 \\
\hline Omacor & Holland & Jan 2017 & Vit E & & 460 & 380 \\
\hline Omacor & Holland & Mar 2017 & Vit E & & 460 & 380 \\
\hline Omacor & Holland & Apr 2017 & Vit E & & 460 & 380 \\
\hline Omacor & Holland & Jul 2017 & Vit E & & 460 & 380 \\
\hline Omacor & Holland & Sep 2017 & Vit E & & 460 & 380 \\
\hline Omacor & Holland & Sep 2018 & Vit E & & 460 & 380 \\
\hline Smarty & UAE & Sep 2017 & & & 60 & 282 \\
\hline Sedico & Egypt & Feb 2017 & & & 180 & 120 \\
\hline Sedico & Egypt & Dec 2017 & & & 180 & 120 \\
\hline GNC & USA & Jun 2018 & Vit E & & 180 & 120 \\
\hline 21st Century & USA & Dec 2017 & & $\begin{array}{l}\text { Herring, anchovy, mackerel, } \\
\text { Sardine, sprat, salmon }\end{array}$ & 70 & 45 \\
\hline 21st Century & USA & Apr 2018 & & $\begin{array}{l}\text { Herring, anchovy, mackerel, } \\
\text { Sardine, sprat, salmon }\end{array}$ & 70 & 45 \\
\hline Nature's Bounty & USA & Dec 2017 & Mixed natural tocopherol & $\begin{array}{l}\text { Herring, anchovy, mackerel, } \\
\text { Sardine }\end{array}$ & 647 & 253 \\
\hline Nature's Bounty & USA & July 2017 & Mixed natural tocopherol & $\begin{array}{l}\text { Herring, anchovy, mackerel, } \\
\text { Sardine }\end{array}$ & 647 & 253 \\
\hline Mar in Oil & Spain & Feb 2017 & Vit E & Salmon & 90 & 60 \\
\hline Mn Marnys & Spain & Mar 2017 & Vit E & Salmon & 90 & 60 \\
\hline Mn Marnys & Spain & Jun 2017 & Vit E & Salmon & 90 & 60 \\
\hline
\end{tabular}

EPA- eicosapentaenoic acid; DHA- docosahexaenoic acid 
The total oil content in capsules (g/capsule) was also measured by the difference in weight between the whole capsule and the weight of the capsule gelatin. The oil is a capsule was collected by pinching a tiny hole in capsules and then squeezing the oil out by hand.

The methylation of fatty acids was done using the two steps procedure as outlined by (Kramer et al., 1997). Briefly, $0.1 \mathrm{~g}$ of the composite oil sample was placed into a screw capped culture tube and a $1 \mathrm{~mL}$ of prepared internal standard was then added. Two $\mathrm{mL}$ of sodium methoxide- $0.5 \mathrm{M}$ solution in methanol was then added to each tube and then incubated in a $50^{\circ} \mathrm{C}$ water bath for 10 min. Tubes where then removed from the water bath and allowed to cool for $5 \mathrm{~min}$. Subsequently, we uncapped the tube and added $3 \mathrm{~mL}$ of $5 \%$ methanolic $\mathrm{HCl}$ to each tube and then the tubes incubated in $80^{\circ} \mathrm{C}$ water bath for $10 \mathrm{~min}$. Tubes were then removed from the water bath and cooled for $7 \mathrm{~min}$ before adding $2 \mathrm{~mL}$ of hexane and $7.5 \mathrm{~mL} \mathrm{6 \%}$ potassium carbonate. Tubes were then centrifuged at $1200 \mathrm{rpm}$ (Centra-GP8, Needham Heights, MA, international equipment company) for $5 \mathrm{~min}$ to separate layers and the supernatant was transferred to 2 $\mathrm{mL}$ vials for Gas Chromatography (GC) analysis.

The methylated fatty acids were analyzed via $\mathrm{A}$ Shimadzu GC-2010 gas chromatograph (Shimadzu Scientific Instruments Inc., Columbia, MD, USA), with a 100-m SP-2560 fused silica capillary column (Restek Stabil WAXDA column, Bellefonte, PA, USA). The GC temperature was programmed to $130^{\circ} \mathrm{C}$ for $60 \mathrm{~min}$, increased at $3^{\circ} \mathrm{C} / \mathrm{min}$ to a final temperature of $250^{\circ} \mathrm{C}$, which was held for $10 \mathrm{~min}$. The column temperature was maintained at $130^{\circ} \mathrm{C}$ and flame ionization detector temperature at $250^{\circ} \mathrm{C}$. The injector and detector temperatures were set at $255^{\circ} \mathrm{C}$. Peaks were identified by comparing the retention times with those of the corresponding standards (Nu-ChekPrep., Elysian, MN; Supelco, Bellefonte, PA; and Larodan Fine Chemicals, Malmo, Sweden).

\section{Results}

Information about the omega-3 supplement samples used in this study is presented in Table 1 . There were thirteen different brands of omega-3 supplements manufactured in eight different countries. The omega-3 supplements samples were from the USA (3 brands), UK ( 2 brands), Spain ( 2 brands), Canada (1 brand), Denmark ( 1 brand), Holland (1 brand), Egypt (1 brand), UAE (1 band) and Saudi Arabia (1 brand). Only brands manufactured in the USA, Canada and Spain specified the type of fish oil used in the product (i.e., salmon, herring, anchovy, mackerel and sardine). Vitamin E was used as an antioxidant in seven brands and six brands did not list any antioxidants in their label.
The Long-Chain Unsaturated Fatty Acids (LCUFA) composition for the omega-3 supplements are presented in Table 2. The LCUFA ranged from 30 to $92 \%$ of the total fatty acids. The EPA and DHA were the main fatty acids in most supplements accounting for 58 to $97 \%$ of the total LCUFA. However, in three brands (21st Century, Mar in Oil and Mn Marnys), EPA and DHA accounted for less than $18 \%$ of the total LCUFA (7.5-17.4\%). In these three brands, C18 unsaturated fatty acids were the main fatty acids ranging from 44 to $65 \%$ of the total LCUFA.

The measured EPA and DHA contents in the omega3 supplements was compared to the contents claimed in the product labels using three reference ranges (Table 3). A reference range between $90-110 \%$ of the manufacturer's claimed contents was the standard and in compliance, a reference range between $80-120 \%$ of the manufacturer's claimed contents was substandard but still in compliance and a reference range with $<80$ or $>120 \%$ of the manufacturer's claimed contents was non-compliant. Using the above arbitrary reference range, only $21.9 \%$ of the supplements fall in the standard compliance range for EPA and DHA. Of the total supplements tested, $56.3 \%$ where in noncompliance for EPA and $59.4 \%$ were in noncompliance for DHA (Table 3). Therefore, using the U.S. Food and Drug Administration (US FDA, 2019) labeling requirements where a supplement must contain at least $80 \%$ of the stated label amount of each component listed, only $44-41 \%$ of the supplements were complainant for EPA and DHA.

There is a wide variation between measured versus claimed amount of omega-3 fatty acids. Nine samples did not specify the amount of omega-3 fatty acids on the label. The range of measured EPA was 5.9 to $540.0 \mathrm{mg}$ per capsule and for DHA was 12.0 to 410.9 mg per capsule.

The stated label amount for EPA (in \%) is in Fig. 1. The percentage of the stated label amount for EPA ranged from 6.5 to $138.6 \%$. Only eight supplements $(25.8 \%)$ contained at least $100 \%$ of the stated label-claim for EPA. Therefore, 23 supplements (74\%) contained less than the stated label amount of EPA. Seven supplements $(22.5 \%)$ contained less than $50 \%$ of the claimed EPA content with four of them containing less than $25 \%$ of the label claim.

The stated label amount for DHA (in \%) is depicted in Fig. 2. The percentage of the stated label amount for DHA ranged from 10.9 to $126 \%$. Only four $(12.9 \%)$ supplements contained at least $100 \%$ of the stated label claim for DHA. Therefore, 27 supplements (87\%) contained less than the stated label amount of DHA as illustrated in Fig. 2. Eight supplements $(25.8 \%)$ contained less than $50 \%$ of the claimed DHA content with two of them containing less than $15 \%$ of the label claim. 
Fatmah Alghamdi et al. / American Journal of Animal and Veterinary Sciences 2020, 15 (4): 315.322 DOI: 10.3844/ajavsp.2020.315.322

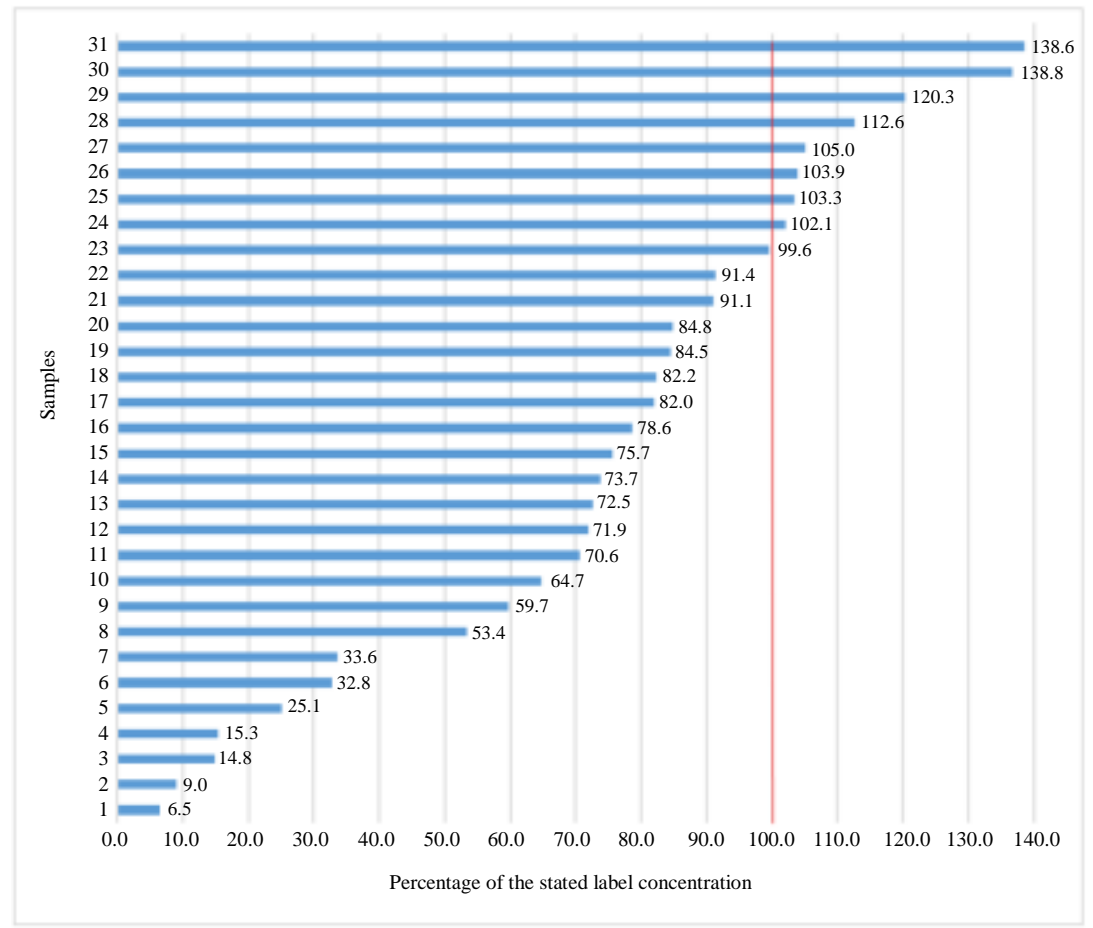

Fig. 1: Stated label concentration (\%) of Eicosapentaenoic Acid (EPA)

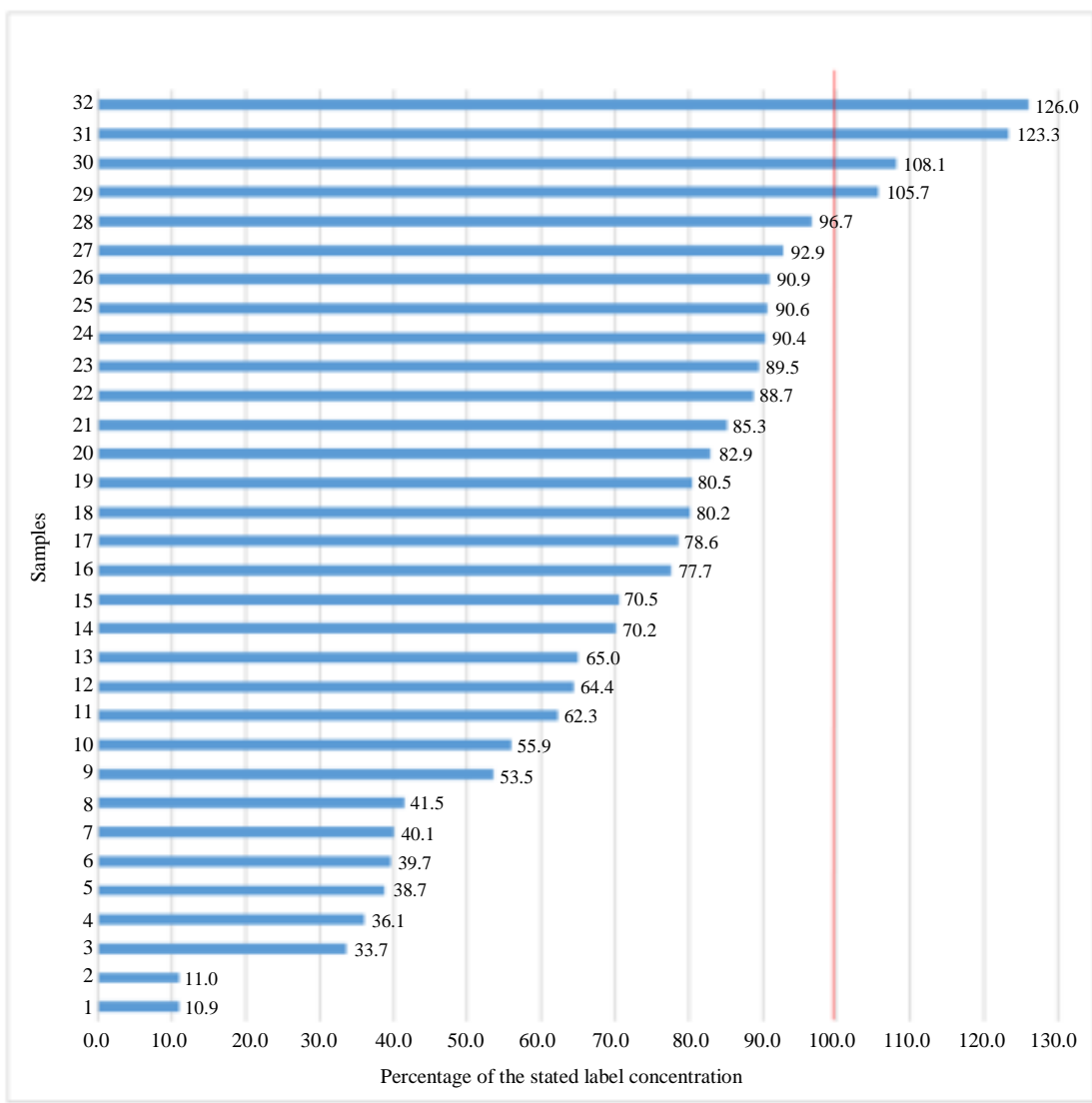

Fig. 2: Stated label concentration (\%) of Docosahexaenoic Acid (DHA) 


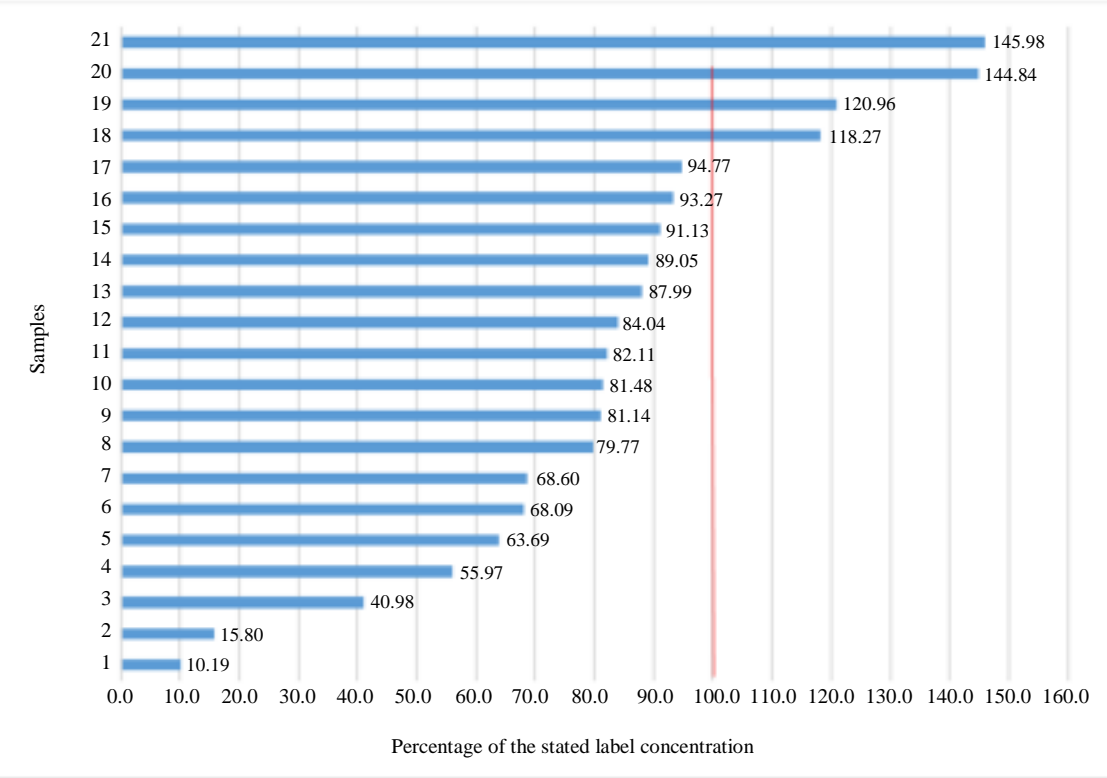

Fig. 3: Stated label concentration (\%) of total omega-3 fatty acids

Table 2: Fatty acid composition (g/100 g of fatty acids) for the omega-3 supplements

\begin{tabular}{|c|c|c|c|c|c|c|c|}
\hline Product name & $\mathrm{C} 18: 1 n 9$ & C18:2n6 & $\mathrm{C} 18: 3 n 3$ & C20:5 (EPA) & $\mathrm{C} 22.5 n 3$ & C22:6 (DHA) & LCUFA \\
\hline Maxepa Forte & 2.21 & 2.08 & 2.06 & 31.83 & 4.87 & 23.38 & 66.43 \\
\hline Maxepa Forte & 2.23 & 1.40 & 2.21 & 32.45 & 4.30 & 24.08 & 66.67 \\
\hline Bio Marine & 4.82 & 1.79 & 1.93 & 33.67 & 4.51 & 22.86 & 69.58 \\
\hline Bio Marine & 4.81 & 1.77 & 1.91 & 33.36 & 4.49 & 23.76 & 70.10 \\
\hline Bio Marine & 2.70 & 5.07 & 2.14 & 31.20 & 4.71 & 22.32 & 68.14 \\
\hline Bio Marine & 11.89 & 5.20 & nd & 35.92 & 4.70 & 25.29 & 83.00 \\
\hline Jamieson & 11.91 & 3.35 & 2.76 & 18.08 & 2.25 & 11.30 & 49.65 \\
\hline Jamieson & 9.90 & 3.79 & 3.13 & 18.71 & 2.43 & 12.17 & 50.13 \\
\hline Vitabiotics & 10.99 & 1.79 & 1.62 & 34.15 & 2.93 & 22.39 & 73.87 \\
\hline Vitabiotics & 11.43 & 1.89 & 1.73 & 35.95 & 3.23 & 23.08 & 77.31 \\
\hline JP Omega 3 & 2.14 & nd & 2.51 & 45.53 & 11.06 & 20.70 & 81.94 \\
\hline JP Omega 3 & 1.82 & 0.48 & 2.57 & 44.37 & 11.93 & 20.01 & 81.18 \\
\hline JP Omega 3 & 2.55 & nd & 3.54 & 51.16 & 10.39 & 19.23 & 86.87 \\
\hline JP Omega 3 & 4.97 & nd & 2.63 & 45.91 & 6.44 & 20.29 & 80.24 \\
\hline Omacor & nd & nd & 2.24 & 46.73 & 2.95 & 39.29 & 91.21 \\
\hline Omacor & nd & nd & 2.23 & 46.56 & 2.96 & 39.61 & 91.36 \\
\hline Omacor & nd & nd & nd & 55.37 & 2.99 & 34.02 & 92.38 \\
\hline Omacor & nd & nd & nd & 52.30 & 3.34 & 35.08 & 90.72 \\
\hline Omacor & nd & nd & 1.79 & 52.10 & 3.30 & 32.62 & 89.81 \\
\hline Omacor & nd & nd & 1.53 & 52.31 & 3.44 & 34.77 & 92.05 \\
\hline Smarty & 0.81 & 1.00 & 8.05 & 13.94 & 8.65 & 54.65 & 87.10 \\
\hline Sedico & 10.30 & 8.09 & 2.88 & 18.62 & 1.91 & 13.08 & 54.88 \\
\hline Sedico & 8.03 & 3.93 & 2.99 & 18.84 & 2.50 & 12.87 & 49.16 \\
\hline GNC & 2.88 & 3.41 & 2.77 & 18.29 & 0.49 & 2.08 & 29.92 \\
\hline 21st Century & 1.60 & 23.82 & 18.50 & 6.27 & nd & 3.17 & 53.36 \\
\hline 21st Century & 17.12 & 18.92 & 26.59 & 5.18 & nd & 2.89 & 70.70 \\
\hline Nature's Bounty & nd & 1.83 & 6.33 & 55.41 & 3.95 & 17.12 & 84.64 \\
\hline Nature's Bounty & 1.88 & 2.63 & 6.98 & 52.85 & 4.70 & 19.85 & 88.89 \\
\hline Mar in Oil & 47.81 & 15.64 & 1.63 & 2.03 & 1.01 & 3.30 & 71.42 \\
\hline Mar in Oil & 41.49 & 13.80 & 1.73 & 4.56 & 2.28 & 7.95 & 71.81 \\
\hline Mn Marnys & 42.42 & 14.05 & 1.71 & 4.47 & 2.06 & 7.40 & 72.11 \\
\hline Mn Marnys & 42.97 & 14.31 & 1.70 & 4.42 & 1.92 & 6.74 & 72.06 \\
\hline
\end{tabular}

EPA- Eicosapentaenoic Acid; DHA- Docosahexaenoic Acid nd: not detected

LCUFA- Long-Chain Unsaturated Fatty Acids (C18:1+C18:2+C18:3+ EPA+ DHA+C22:5) 
Table 3: Percentage of samples within $0-10 \%, 10-20 \%$ and $>20 \%$ of the label claim

\begin{tabular}{lll} 
& C20:5n3 & \\
& $(\mathrm{EPA})(\%)$ & C22:6n3 \\
& 21.88 & 21.88 \\
\hline $0-10 \%$ & 21.88 & 18.75 \\
$10-20 \%$ & 56.25 & 59.38 \\
$>20 \%$ & DHA) & \\
\hline
\end{tabular}

EPA- Eicosapentaenoic Acid; DHA- Docosahexaenoic Acid

Only 21 samples reported the total omega-3 fatty acids content (Fig. 3). The total omega-3 concentration ranged from 10.2 to $146.0 \%$ of the stated label concentration. Only 4 (19\%) supplements contained at least $100 \%$ of the stated label claim for total omega-3 concentration. Therefore, 17 supplements (80.9\%) contained less than the stated label amount of total omega-3 concentration as illustrated in Fig. 3.

\section{Discussion}

The consumption of omega-3 fatty acids has gained popularity in Arab Gulf Countries. The omega3 supplements are mainly imported from different countries, while small amount of omega-3 supplements sold in Arab Gulf Countries are encapsulated locally. Although the Gulf Cooperation Council Standardization Organization (GSO) and the food and drug authorities of local governments regulate the omega- 3 oil supplements in the region, there is still no available data on the quality of omega3 supplements sold in the region. To the best of our knowledge, this is the first study to evaluate the label claims of omega-3 supplements sold in the Arabic Gulf Countries.

In the current study, the EPA content of supplements was higher than that of DHA, except for the Smarty product. This may be due to the type of oil used in the supplements. Fish and krill oils are characterized by a higher EPA content (Kleiner et al., 2015), while DHA content is higher in algae oil (Fedorova-Dahms et al., 2011). In the current study, the omega-9/omega- 6 fatty acid contents of supplements were lower than that of omega-3 fatty acids. However, the omega-9/omega-6 fatty acid contents of 21st Century, Mar in Oil and Mn Marnys were higher than that of omega-3 fatty acids. The EPA and DHA contents of these brand were also significantly varied sugesting these supplements contained vegetable oils rich in omega-9/omega-6 fatty acid in addition to fish or algea oil (Malainey et al., 1999; Mann et al., 2003).

In the current study, results showed a wide variation between measured vs claimed EPA and DHA amounts consistent with the findings from previously published studies from other countries. For example, (Opperman et al., 2011) tested 45 commercially available omega-3 supplements sold in
South Africa and found $56 \%$ contained less than $90 \%$ of the EPA and DHA amounts stated on the label. Fierens and Corthout (2007) also examined 16 commercially available fish oil products in Europe and obtained similar results to this study, with seven products failing to meet label claims for EPA and/or DHA. Fantoni et al. (1996) examined 16 different encapsulated omega-3 supplement products in Brazil. Of these samples, only five stated EPA and DHA contents on the label and two were found to be below the stated amount. Kleiner et al. (2015) analyzed EPA and DHA from 47 commercial supplements in the United States. They found that $74 \%$ of the supplements tested contained less than the stated label amount of EPA and DHA. However, (Hamilton et al., 2010) observed a close agreement between supplements tested and the stated label of omega-3 content sold in Australia. Tatarczyk et al. (2007) found that all omega-3 products in Austria met their label claims. These different results suggest that adherence to quality of omega- 3 fatty acids may vary according to the country of production.

The total omega-3 fatty acid concentration in the tested supplements ranged from 31.4 to $1009.0 \mathrm{mg}$ per capsule and the concentrations were different between the different samples of the same brand (e.g., Bio Marine, JP Omega 3, Nature's Bounty, 21st Century, Mar in Oil and Mn Marnys). The inconsistent values in the same brand might be attributed to infrequent or poor batch-control analyses during the encapsulation. In general, a wide variation during the encapsulation leads to an increase in the variation in the final omega-3 fatty acid content of the supplements (Albert et al., 2015).

The wide variability of measured versus claimed concentrations could also be related to the seasonal variation in the fatty acid profile of fish tissues (Gamez-Meza et al., 1999). Furthermore, fish from different sources (i.e., farmed or wild) may also have different dietary levels of fatty acids, based on feeding regimens (Jangaard et al., 1967; Iverson et al., 2002; Sprague et al., 2016). Additionally, the differences in omega-3 fatty acid profile may be due to fatty acid oxidation and degradation during encapsulation, packing, transport, storage and analysis. Several researchers speculated that oxidative damage was possibly the main reason for the loss of EPA and/or DHA in omega-3 supplements (Chee et al., 1990; Srigley and Rader, 2014). Albert et al. (2015) obtained a positive relationship the loss of EPA and DHA values with oxidative damage. In contrast, (Sprague et al., 2018) did not observe any relationship between the loss of EPA and DHA contents and oxidative damage.

\section{Conclusion}

The current study's results showed a wide range between the stated label concentrations of EPA and DHA 
in omega-3 supplements with the majority of omega-3 dietary supplements sold in Arab Gulf Countries contain less than the stated label amount of EPA and DHA. The results indicate the need for governmental agencies to improvement in the regulation of omega-3 dietary supplements and in the quality assurance processes of omega-3 supplement's manufacturers.

\section{Authors' Contributions}

Fatmah Alghamdi: Conduction of study, analysis and interpretation of data, drafting of manuscript.

Mohammed G. Embaby: Laboratory analysis.

Mevlüt Günal: Drafting of manuscript.

Amer A. AbuGhazaleh: Experimental design, interpretation of data and drafting of manuscript.

\section{Ethics}

This article is original and contains unpublished material. The corresponding author confirms that all of the other authors have read and approved the manuscript and no ethical issues involved.

\section{Disclosure Statement}

The authors warrant that there are no conflicts of interests among authors and between authors and other people, institutions or organizations.

\section{References}

Albert, B. B., Derraik, J. G., Cameron-Smith, D., Hofman, P. L., Tumanov, S., Villas-Boas, S. G., ... \& Cutfield, W. S. (2015). Fish oil supplements in New Zealand are highly oxidised and do not meet label content of n-3 PUFA. Scientific Reports, 5, 7928.

Alhyas, L., McKay, A., Balasanthiran, A., \& Majeed, A. (2011). Prevalences of overweight, obesity, hyperglycaemia, hypertension and dyslipidaemia in the Gulf: systematic review. JRSM Short Reports, 2(7), 1-16.

Al-Rubeaan, K., Al-Manaa, H., Khoja, T., Ahmad, N., Al-Sharqawi, A., Siddiqui, K., ... \& Al-Otaibi, M. (2014). The Saudi abnormal glucose metabolism and diabetes impact study (SAUDI-DM). Annals of Saudi Medicine, 34(6), 465-475.

Chee, K. M., Gong, J. X., Rees, D. M. G., Meydanl, M., Ausman, L., Johnson, J., ... \& Schaefer, E. J. (1990). Fatty acid content of marine oil capsules. Lipids, 25(9), 523-528.

ConsumerLab. (2019). Best fish oil? ConsumerLab.com. Retrieved on May 12, 2019 from: https://www.consumerlab.com/m/news/best\%2Dfish $\% 2$ Doil/
DeFilippis, A. P., Blaha, M. J., \& Jacobson, T. A. (2010). Omega-3 fatty acids for cardiovascular disease prevention. Current Treatment Options in Cardiovascular Medicine, 12(4), 365-380.

Fantoni, C. M., Cuccio, A. P., \& Barrera-Arellano, D. (1996). Brazilian encapsulated fish oils: Oxidative stability and fatty acid composition. Journal of the American Oil Chemists' Society, 73(2), 251-253.

Fedorova-Dahms, I., Marone, P. A., Bauter, M., \& Ryan, A. S. (2011). Safety evaluation of DHA-rich algal oil from Schizochytrium sp. Food and Chemical Toxicology, 49(12), 3310-3318.

Fierens, C., \& Corthout, J. (2007). Omega-3 fatty acid preparations--a comparative study. Journal de Pharmacie de Belgique, 62(4), 115-119.

Gamez-Meza, N., Higuera-Ciapara, I., De La Barca, A. C., Vázquez-Moreno, L., Noriega-Rodriguez, J., \& Angulo-Guerrero, O. (1999). Seasonal variation in the fatty acid composition and quality of sardine oil from Sardinops sagax caeruleus of the Gulf of California. Lipids, 34(6), 639-642.

GOED. (2019). Global recommendations for EPA and DHA intake. Global Organization for EPA and DHA (GOED). Retrieved on April 21, 2019 from: https://goedomega3.com/

Grand View Research, 2019. Omega 3 market size, share and trends analysis report by application, by region and segment forecasts, 2019-2025. https://www.reportlinker.com/p05982325/?utm_sour ce $=\mathrm{GNW}$

Hamilton, K., Brooks, P., Holmes, M., Cunningham, J., \& Russell, F. D. (2010). Evaluation of the composition of omega-3 fatty acids in dietary oil supplements. Nutrition and Dietetics, 67(3), 182-189.

Holub, D. J., \& Holub, B. J. (2004). Omega-3 fatty acids from fish oils and cardiovascular disease. Molecular and Cellular Biochemistry, 263(1), 217-225.

Hunter, J. E. (1990). n-3 fatty acids from vegetable oils. American Journal of Clinical Nutrition, 51(5), 809-814.

Iverson, S. J., Frost, K. J., \& Lang, S. L. (2002). Fat content and fatty acid composition of forage fish and invertebrates in Prince William Sound, Alaska: factors contributing to among and within species variability. Marine Ecology Progress Series, 241, 161-181.

Jangaard, P. M., Ackman, R. G., \& Sipos, J. C. (1967). Seasonal changes in fatty acid composition of cod liver, flesh, roe and milt lipids. Journal of the Fisheries Board of Canada, 24(3), 613-627.

Kaur, N., Chugh, V., \& Gupta, A. K. (2014). Essential fatty acids as functional components of foods-a review. Journal of Food Science and Technology, 51(10), 2289-2303. 
Kinsella, J. E. (1990). Sources of Omega-3 Fatty Acids in Human Diets. In: Omega-3-Fatty Acids in Health and Disease, Lees, R.S. and M. Kate1 (Eds.), Marcel Dekker, New York, pp: 157-200.

Kleiner, A. C., Cladis, D. P., \& Santerre, C. R. (2015). A comparison of actual versus stated label amounts of EPA and DHA in commercial omega-3 dietary supplements in the United States. Journal of the Science of Food and Agriculture, 95(6), 1260-1267.

Kramer, J. K., Fellner, V., Dugan, M. E., Sauer, F. D., Mossoba, M. M., \& Yurawecz, M. P. (1997). Evaluating acid and base catalysts in the methylation of milk and rumen fatty acids with special emphasis on conjugated dienes and total trans fatty acids. Lipids, 32(11), 1219-1228.

Malainey, M. E., Przybylski, R., \& Sherriff, B. L. (1999). The fatty acid composition of native food plants and animals of western Canada. Journal of Archaeological Science, 26(1), 83-94.

Mann, N. J., Sinclair, A. J., Percival, P., Lewis, J. L., Meyer, B. J., \& Howe, P. R. (2003). Development of a database of fatty acids in Australian foods. Nutrition and Dietetics, 60(1), 42-45.

Opperman, M., Benade, A. S., \& Marais, D. W. (2011). Analysis of omega-3 fatty acid content of South African fish oil supplements. Cardiovascular Journal of Africa, 22(6), 324.

Sprague, M., Cooper, S., Tocher, D. R., \& Betancor, M. B. (2018). Encapsulated fish oil products available in the UK meet regulatory guidelines with respect to EPA+ DHA contents and oxidative status. European Journal of Lipid Science and Technology, 120(10), 1800105.

Sprague, M., Dick, J. R., \& Tocher, D. R. (2016). Impact of sustainable feeds on omega-3 long-chain fatty acid levels in farmed Atlantic salmon, 2006-2015. Scientific Reports, 6(1), 1-9.
Srigley, C. T., \& Rader, J. I. (2014). Content and composition of fatty acids in marine oil omega-3 supplements. Journal of Agricultural and Food Chemistry, 62(29), 7268-7278.

Stenson, W. F., Cort, D., Rodgers, J., Burakoff, R., DeSchryver-Kecskemeti, K., Gramlich, T. L., \& Beeken, W. (1992). Dietary supplementation with fish oil in ulcerative colitis. Annals of Internal Medicine, 116(8), 609-614.

Tapiero, H., Ba, G. N., Couvreur, P., \& Tew, K. D. (2002). Polyunsaturated fatty acids (PUFA) and eicosanoids in human health and pathologies. Biomedicine and Pharmacotherapy, 56(5), 215-222.

Tatarczyk, T., Engl, J., Ciardi, C., Laimer, M., Kaser, S., Salzmann, K., ... \& Ebenbichler, C. F. (2007). Analysis of long-chain $\omega-3$ fatty acid content in fishoil supplements. Wiener Klinische Wochenschrift, 119(13-14), 417-422.

US FDA. (2019). Guidance for Industry: Nutrition Labeling Manual. A Guide for Developing and Using Data Bases. U.S. Food and Drug Administration. Retrieved on April 5, 2019 from: https://www.fda.gov/Food/GuidanceRegulation/Gui danceDocumentsRegulatoryInformation/LabelingNu trition/ucm063113.htm

Vu, T. T., Dieterich, P., Vu, T. T., \& Deussen, A. (2019). Docosahexaenoic acid reduces adenosine triphosphate-induced calcium influx via inhibition of store-operated calcium channels and enhances baseline endothelial nitric oxide synthase phosphorylation in human endothelial cells. The Korean Journal of Physiology and Pharmacology, 23(5), 345-356.

Whelan, J., \& Rust, C. (2006). Innovative dietary sources of $n-3$ fatty acids. Annual Review of Nutrition, 26, 75-103. 